\title{
ROTAS HORIZONTAIS: CAMINHOS DA CRÍTICA LITERÁRIA LATINO-AMERICANA DO PRESENTE
}

\author{
Ariadne Costa da Mata
}

\begin{abstract}
RESUMO
Nos últimos anos, a tendência à horizontalidade se tornou visível, particularmente, nos movimentos sociais, mas também além deles. Ela indica uma nova arquitetura das organizaçóes humanas e pede mudanças no modo como o conhecimento é produzido e organizado. Mais que uma simples eliminação de fronteiras entre campos antes distinguíveis, a horizontalidade implica a descentralização e disseminação do poder.
\end{abstract}

PALAVRAS-CHAVE: Horizontalidade; Estudos Literários; Contemporaneidade

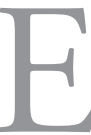

ste trabalho parte da tentativa de entender algumas das questóes centrais sobre os modos de vida no presente. Ele é fruto de uma reflexão sobre o modo como se organizam as relaçôes sociais hoje, mas é motivado, sobretudo, pela intuição de que não é suficiente adotar o contemporâneo como objeto de estudo. Seria preciso, também, pensar em práticas de atuação, modos de produção e difusão do conhecimento que fossem, eles mesmos, contemporâneos.

Parto de uma anedota pessoal. Todos nós nos lembramos o que estávamos fazendo na manhã de 11 de setembro de 2001, quando aconteceram os ataques às torres gêmeas. Como muita gente, eu vi, em casa e em tempo real, o segundo aviáo atingir o edifício e, como todo mundo naquele momento, náo entendia muito bem o que estava acontecendo, exceto que era muito importante. $\mathrm{O}$ que todos pareciam saber era que aquele evento ia reverberar no resto do mundo com consequências de longo prazo, grande parte delas 
imprevisíveis, atingindo pessoas e nações muito além daquelas diretamente envolvidas. Ao mesmo tempo, esse incidente não era como uma catástrofe natural que irrompe subitamente, mas uma continuidade. Ele havia começado antes, lentamente; ele não era completamente absurdo. Naqueles dias eu escrevia uma dissertação de mestrado sobre a representação da violência no cinema de Stanley Kubrick e sentia que, de algum modo, havia uma conexão entre o que eu via em seus filmes e o que eu testemunhava naquele momento específico da história. Recordo a sensação de impotência, porque era evidente que havia uma ligação entre todas as coisas, mas, infelizmente eu não era capaz de explicá-la. Hoje, passada a fase obsessiva em que o estudante vê todo o universo pela ótica de seu projeto, eu continuo acreditando nessa conexão. E sigo sem ser capaz de explicá-la, mas agora eu não creio que eu possa realmente fazer isso sozinha.

Uma impressão parecida me causa a sucessão de eventos que se iniciaram com as revoltas no Oriente Médio desde dezembro de 2010, seguidas das manifestaçóes dos Indignados, em Madri, que eclodiram em 15 de maio de 2011 e, em seguida, com a ocupação da Praça da Liberdade, em Wall Street, no setembro seguinte, justamente quando se cumpriam dez anos dos ataques às torres. Esses acontecimentos, todos fisicamente tão longe de nós e com tantas particularidades e diferenças entre si, parecem, entretanto, evidenciar mudanças que nos afetam a todos. Creio ser importante pensá-los não só porque eles tornaram o presente muito mais interessante, mas porque, de algum modo, também nos envolvem. Algumas vezes na história, irrompem eventos que, pelo alcance de seus efeitos, tornam a complexidade muito mais evidente. Eles atuam como uma espécie de líquido de contraste, fazendo brilhar as conexóes da sociedade globalizada e mutuamente dependente. As revoltas e movimentos como a Primavera Árabe, o M-15 e o Occupy têm algo a nos ensinar, me parece, sobre o estar no mundo hoje. Eles são sintomáticos de, ou anunciam uma reorganização (ou desorganização) das formas de convivência. Para dizer de uma maneira bem simples, eles indicam uma configuração diferente dos modos como as pessoas se juntam para fazer coisas.

Guardadas as proporçóes, os três eventos apresentam muitas semelhanças. Irrompem de modo aparentemente espontâneo, sem liderança, se organizam de forma não hierárquica. São açóes políticas desinstitucionalizadas, ou seja, se produzem e se mantêm à margem de (quando não diretamente 
opostas a) instituições que funcionaram tradicionalmente como instâncias de legitimação: o Estado, os partidos políticos, os sindicatos. Pela sua própria estrutura, essas organizaçóes apresentam um alto grau de imprevisibilidade. Elas se impóem como movimentos contra, definindo-se pelo que recusam, pelo que não querem, escapando à formulação de um projeto, mantendo-se deliberadamente em uma zona tensa de indefinição. Justamente nesse aspecto reside sua radicalidade e também sua fragilidade, a maior dificuldade para sua manutenção.

Creio ser possível pensar no conjunto dessas características por meio da noção horizontalidade: uma arquitetura das organizaçóes que aparece de modo gritante nesses movimentos e que se encontra, também, em uma série de outras manifestaçóes contemporâneas; inclusive, creio, na produção de conhecimento em certos contextos, o que inclui (ou pode incluir) a literatura e os estudos literários. O que procuro não é uma relação direta, referencial, entre esses acontecimentos e a literatura, mas pensar que certos traços da ficção e da crítica contemporâneas guardam semelhanças com essas organizaçóes e manifestações porque compartilham com elas uma sensibilidade que não seria possível em outro momento da história.

A ideia de horizontalidade aparece inicialmente - até onde pude traçar seu histórico -, ligada a gestão de negócios, para designar organizaçôes que assumem uma estrutura desierarquizada, em que as decisóes são tomadas de forma coletiva e a responsabilidade é difundida entre os membros do grupo. Ela se opóe, evidentemente, à verticalidade das instituiçóes tradicionais e implica uma distribuição do poder. Em termos políticos, a passagem da verticalidade para a horizontalidade se dá como transição das democracias representativas, nas quais um indivíduo eleito representa a todos, para os projetos de democracia direta ou ação direta, sem interferência de um poder centralizador.

No âmbito dos movimentos sociais, antes mesmo dos eventos que mencionei, o termo vem sendo apropriado e ressignificado para designar soluçóes coletivas em tempos de crise do capitalismo. Marina Sitrin ${ }^{1}$ chama Horizontalism a seu livro dedicado às distintas organizaçóes de trabalhadores desempregados na Argentina que surgiram no pico da crise de 2001, primeiramente em

1 SITRIN, Marina (ed.). Horizontalism. Voices of Popular Power in Argentina. Oakland: AK Press, 2006. 
torno das assembleias de bairros. Muitos desses movimentos se dissolveram com o passar do tempo, outros derivaram em movimentos mais tradicionais ou foram cooptados ou absorvidos por partidos políticos de esquerda. Outros permaneceram horizontais e se tornaram organizaçóes produtivas nas quais prevaleceu a autogestão e a autonomia. A horizontalidade significou, para esses movimentos, como mostra Sitrin, tanto a meta, como a ferramenta, ou seja, a horizontalidade era um objetivo a ser alcançado mas também o método para construir organizaçóes não autoritárias, não-hierárquicas, como decisôes tomadas por meio do consenso. (Sitrin, 2006, p. 10-19) Não coincidentemente, a mesma autora estaria, dez anos depois, envolvida ativamente com o movimento Occupy, atuando como advogada dos ativistas detidos pela polícia de Nova York.

A horizontalidade é o traço distintivo dos movimentos que eclodiram desde a revolta na Tunísia. São reações coletivas e endêmicas à insatisfação. Mais claramente no caso dos movimentos ocidentais (M-15 e Occupy), essas reaçôes se baseiam sobretudo em uma oposição ao capitalismo financeiro. Diferentemente dos movimentos estudados por Sitrin, na Argentina, no entanto, as manifestações mais recentes são marcadas pelo uso das tecnologias de comunicação, particularmente das redes sociais. A disponibilidade dessas tecnologias está diretamente ligada à viabilidade de ações horizontais da dimensão que estamos vendo hoje e ao surgimento de uma subjetividade coletiva que não parecia possível antes desta última crise do capitalismo.

Além disso, a horizontalidade previne a identificação desse sujeito coletivo com um indivíduo que personificasse a ideologia; além de não ter projeto, os movimentos não têm, tampouco, um rosto. O sujeito coletivo é, por definição, anônimo. Ninguém responde pela ação e é aí mesmo que reside sua força. Todos seguramente se lembram do subcomandante Marcos, que podia ser muitos e qualquer um. Mas ele ainda tinha um nome, mesmo que de fantasia, o que não ocorre agora. ${ }^{2}$

Existem, nesse momento, uma quantidade impressionante de textos tentando interpretar esses eventos sob diferentes enfoques e tirar deles alguma lição sobre o presente. Mas esse esforço interpretativo é uma continuidade

2 Um interessante exemplo do impacto desse sujeito coletivo: a revista norte-americana Times elegeu como a personalidade do ano de 2011 o ativista anônimo - the protester -, exibindo a imagem de um rosto coberto que poderia ser de um egípcio, de um espanhol, de um nova-iorquino, de qualquer um. 
de outra escrita que, lida hoje, após a eclosão desse movimentos, soa antecipatória. Esses eventos parecem coroar uma série de ideias que vinham se desenvolvendo na teoria produzida nas últimas décadas, encaixando-se nelas como o exemplo que as justifica. É o caso, por exemplo, das ideas sobre a crise e reinvenção do comum e da comunidade de Toni Negri e Judith Revel, ou das ideias sobre a multidão de Paolo Virno e de Howard Rheingold e a noção de subjetividade coletiva desenvolvida por Felix Guattari. Tudo se dá como se a emergência desse sujeito coletivo anônimo e múltiplo fosse pressentida e esperada. Guattari ${ }^{3}$ fala de uma subjetividade "polissêmica, animista, transindividual" e diz que:

Sejam quais forem as viradas da história, parece que a criatividade social está sendo chamada a expropriar os antigos enquadramentos ideológicos rígidos, em particular os que serviam de caução à eminência do poder de Estado e os que ainda fazem do mercado capitalísitico uma verdadeira religião. (Guattari, 1992, p. 121)

Ele reconhece ainda, a necessidade de se pensar essa subjetividade à partir da interação com a máquina, inerente à cultura contemporânea.

Em 2002, quando a vida cotidiana ainda não estava povoada de telefones celulares e a Internet portátil não era uma realidade, Howard Rheingold prognosticava o surgimento de multidóes inteligentes capazes de se organizar por caminhos transversais, à margem e revelia do Estado, justamente devido a seu acesso à tecnologia: "multidóes inteligentes são compostas por pessoas capazes de agir em conjunto mesmo sem se conhecerem (...) Quando a Internet móvel realmente chegar, ela não será apenas um modo de executar velhas ações em trânsito. Ela será um modo de fazer coisas que nunca antes poderiam ser feitas." (Minha tradução) (Rheingold, 2002, p. 166) ${ }^{4}$ A horizontalidade, estimulada pela tecnologia, permite uma colaboração sem precedentes. A capacidade de ação coletiva através da tecnologia é central para

3 GUATTARI, Félix. Caosmose - Um novo paradigma estético. Trad. Ana Lúcia de Oliveira e Lúcia Cláudia Leão. São Paulo: 34, 2012.

4 RHEINGOLD, Howard. Smart Mobs: the next social revolution. Cambridge: Perseus, 2002. 
Rheingold, mas ele recorda que as multidóes inteligentes são também um risco. A mesma organização que permite cooperação para o interesse comum possibilita atrocidades e pode ser usada para o controle, a vigilância, a subtração de liberdades individuais. (idem, p. 239)

Além dos perigos pensados por Rheingold, no entanto, que se referem muito mais à apropriação das tecnologias pelo Estado, penso que a própria noção de risco hoje está ligada aos traços que associo aqui à horizontalidade: desde a paranoia do terrorismo difuso propagada nos Estados Unidos após o 11 de setembro, passando pelo risco das pandemias, ensaiado no episódio da gripe suína, até a instabilidade econômica de um mercado global. Os medos coletivos contemporâneos parecem girar em torno dos efeitos colaterais da hiperconexão.

Retomando a ideia da nova coletividade, Paolo Virno indica o ressurgimento da categoria de multidão, enterrada nos debates filosóficos do século XVII em favor do conceito de povo. Enquanto a noção de povo implica a unificação sob um Estado, ou seja, sob um poder vertical, o que garantiria a ordem e a unidade da nação, a multidão estaria associada à desordem e ao caos social. Para Virno, é a multidão e não o povo que caracteriza as formas de vida contemporâneas. Ele recupera o conceito de Marx de "general intellect" para designar a "inteligência social", "el conocimiento en cuanto bien común", e afirma que o atual processo de trabalho tem como matéria prima a linguagem, os processos cognitivos e, inclusive, os afetos." Virno afirma, ainda, o seguinte:

A multidão contemporânea não está composta nem por "cidadãos", nem por "produtores". Ela ocupa uma região intermediária entre o "individual" e o "coletivo". Para ela, não vale de nenhum modo a distiçấo entre o "público" e o "privado". E é justamente por causa da dissolução destas duplas durante tanto tempo tidas como óbvias que não se pode falar mais de um povo que converge em uma unidade estatal. (Minha tradução) (Virno, 2003, p. 25) ${ }^{6}$

5 ESPOSITIO, Marcelo. "The Republic of the Multitude - Interview with Paolo Virno". Generation Online. http://www.generation-online.org/t/republicmultitude.htm. 12/07/2012.

6 VIRNO, Paolo. Gramática de la multitud. Trad. Adriana Gómez. Madri: Traficantes de Sueños, 2003. 
Virno também escreve antes da eclosão das manifestaçóes mencionadas aqui, embora seu texto, assim como o de Rheingold, pareça se referir a elas. Essas teorias sobre o contemporâneo parecem ter se tornado muito mais concretas desde então e servem de ponte entre os eventos de alcance global e ideias que circulam na literatura e na crítica latino-americanas recentes.

Tanto Virno como Rheingold são retomados pela crítica argentina Josefina Ludmer em Aqui América Latina ${ }^{7}$, quando ela procura chaves para ler a literatura do presente. O vocabulário de Virno ao tratar da distinção entre multidão e povo ecoa em Ludmer, em sua proposta do conceito de pós-autonomia e sua aposta na desdiferenciação das fronteiras, no fim do pensamento das esferas dentro do âmbito dos estudos literários. Esse eco se ouve, por exemplo, quando ela define os habitantes das ilhas urbanas da ficção contemporânea:

Os habitantes da ilha (os personagens que a narração pode multiplicar, fraturar, esvaziar) parecem ter perdido a sociedade ou algo que a representa na forma da família, classe, trabalho, razão e lei e, as vezes, nação. Se definem no plural e formam uma comunidade que não é a da família nem a do trabalho, nem tampouco a da classe social, mas algo diferente, que pode incluir todas essas categorias ao mesmo tempo, em sincornia e em fusão. (...) Estão fora e dentro ao mesmo tempo: fora da sociedade, na ilha, e dentro da cidade, que é o social. (Minha tradução) (Ludmer, 2010, p. 131).

Não me interessa tanto, neste momento, discutir a validade da ideia de pós-autonomia, que já foi bastante explorada e que a autora mesma modaliza em suas publicaçóes mais recentes. Mas recorro a Ludmer para observar como a horizontalidade que marca determinadas práticas de convivência contemporâneas se fazem presentes tanto na ficção em si como em nossos modos de lê-la. Há dois aspectos fundamentais da horizontalidade que são comuns aos eventos referidos antes (particularmente 15-M e Occupy) e a nossas leituras

7 LUDMER, Josefina. Aqui América Latina. Una especulación. Buenos Aires: Eterna Cadencia, 2010. 
do fenômeno literário contemporâneo: a desierarquização e a deliberada indefinição do projeto.

A crítica contemporânea define a literatura insistentemente como um objeto escorregadio, um objeto que, assim como as açóes coletivas de que eu tratava antes, se define menos pela afirmaçáo de uma identidade do que pelo que se recusa a ser. A ficção contemporânea - dizemos repetidas vezes - é marcada pela obliteração das fronteiras (entre real e ficção ou entre gêneros do discurso, por exemplo).

Estou pensando nos nomes que têm sido dados às expressóes literárias do presente: pós-autônomas, híbridas, heterônimas, mutantes, inespecíficas. Nosso objeto de estudo parece estar em fuga.

Mas se há uma percepção, por parte da crítica, de que um movimento em direçáo à horizontalidade vai se delineando na literatura, o mesmo náo parece acontecer na prática da crítica e dos estudos literários acadêmicos. Ou seja, se a ideia de horizontalidade ou noçóes afins sáo correntes nos textos da crítica atual, do ponto de vista institucional continuamos atuando no paradigma da verticalidade. Os estudos literários são generosos, abrigam incursóes de diferentes campos do saber e direcionam também seu olhar para objetos diversos. Mais do que ler obras, os estudos literários se tornaram uma ferramenta para ler o mundo. Mas ainda operamos majoritariamente dentro de uma definição de áreas determinadas por conceitos de língua e nação, dentro de um divórcio bem marcado entre os campos do conhecimento fora das ciências humanas. Nossa orientação é predominantemente disciplinar, num tempo em que surgem problemas para os quais nenhuma disciplina isoladamente oferece resposta.

Penso aqui nas ideias do crítico latinoamericanista Otmar Ette, ${ }^{8}$ que se queixa da separação entre as ciências humanas e as chamadas "ciências da vida" e lamenta a marginalização das humanidades num momento histórico em que uma pergunta fundamental se coloca à sociedade global: "como culturas radicalmente distintas podem viver juntas com respeito mútuo pelas diferenças de cada uma." (Ette, 2010, p.11) Para Ottmar Ette, os estudos literários deveriam assumir a dianteira e se dedicar a desenvolver um conhecimento aberto, sobre

8 ETTE, Ottmar. "Literature as Knowledge for Living, Literary Studies as Science for Living”.Ed. e trad. Vera M. Kutzinski. PMLA, 125, n. 4, 977-993, outubro de 2010. 
e para a vida em comum. Como parte desse esforço para ver a literatura como conhecimento sobre a convivência, Ette propõe a noção de "literaturas sem residência fixa”: não são simplesmente literaturas de imigração, mas literaturas de trânsito, nas quais se transcende fronteiras, literaturas que não se podem conter nos limites de uma língua ou de uma cultura específica, literaturas onde diferentes culturas convivem. A literatura entra, aí, mais uma vez, como um espaço onde o conhecimento sobre e para a vida circula para além das fronteiras disciplinares que os estudos literários se impóem:

Como um repositório dinâmico e mutável de saber sobre a vida, a literatura imagina e dá forma estética a diretrizes sobre como viver. Por isso, ela recorre a muitos conhecimentos parciais, inclusive ao discurso acadêmico. A literatura se especializa em não ser especializada, com respeito às disciplinas, às realidades vividas e às diferenças culturais. Por isso a literatura nem nega nem fomenta a divisão entre as humanidades e as biociências, e tem acesso a inúmeros códigos de tradiçôes de pensamento radicalmente diferentes. A literatura é, portanto, especialmente capaz de armazenar uma grande variedade de conhecimentos sobre a vida. (Minha tradução). (Ette, 2010, p. 18)

Reconhecê-lo não é problema para a crítica do presente. Mas, talvez, a própria crítica literária desperdice o potencial da literatura ao confiná-la em suas fronteiras disciplinares.

Os eventos antes mencionados aqui nos mostram que o grande capital contemporâneo é a capacidade de cooperação e colaboração, a capacidade de ação conjunta. $\mathrm{O}$ que falta, então, para que de fato exista a cooperação entre áreas na produção do conhecimento?

Penso que teríamos muito a ganhar se a convivência com a diferença de pensamentos ultrapassasse nosso discurso e afetasse também nossa prática profissional, nas pesquisas, nos escritos, na formação que promovemos, no modo como concebemos nossas instituições. 


\title{
HORIZONTAL ROUTES: CURRENT PATHS OF LITERARY CRITICISM IN LATIN AMERICA
}

\begin{abstract}
In the last decades, the tendency towards horizontality became visible, particularly (but not only) in social movements. Horizontality implies a new architecture in human organizations and pushes for changes in the way knowledge is produced and organized. More than a simple erosion of frontiers between fields, horizontality means the decentralization and dissemination of power.

KEYWORDS: Horizontality; Literary Studies; Contemporary times
\end{abstract}

Recebido em: 21/05/2012

Aprovado em: 11/12/2012 